\title{
Land contamination and urinary abnormalities: cause for concern?
}

\author{
B Staples, M L P Howse, H Mason, G M Bell
}

Occup Environ Med 2003;60:463-467

See end of article for authors' affiliations .....................

Correspondence to: Dr B Staples, Consultant Environmental Public Health, HPA (North West),

Vernon Pritchard Court,

57a Upper Northgate Street, Chester CHI 4EF, UK;

brian.staples@hpa.org.uk

Accepted

17 November 2002

\begin{abstract}
Aims: To determine the prevalence of proteinuira and enzymuria among a cohort of subjects exposed to hexachlorobutadiene (HCBD) in their homes and to determine whether there was a change in observed effects when exposure ceased.

Methods: Residents underwent a health check, which included a panel of urinary markers of both glomerular and tubular origin, within two months of cessation of long term exposure to HCBD and again at least 10 months after exposure ceased. Analysis of the results was performed to determine if there was any early evidence of renal effects, and to ascertain whether changes in these parameters occurred after exposure to HCBD ceased.

Results: Tubular proteinuria and enzymuria were increased in the initial health check and significantly decreased after the residents had left their homes for about 10 months. As the early renal tubular markers improved when exposure ceased it is anticipated that the long term nephrotoxic risk will be minimal, but the carcinogenic risk remains unknown.

Conclusions: Results show there was a renal effect which improved when subjects left their homes. This suggests there was a local environmental factor responsible for the observations. This is consistent with the predicted toxicological effects of HCBD from animal studies.
\end{abstract}

$\mathrm{T}$ he United Kingdom has a legacy of contaminated land as a result of past industrial, mining, and waste disposal activities. It has been estimated that there are between 50000 and 100000 potentially contaminated sites across the nation. Local authorities have longstanding duties in relation to environmental issues. New legislation with effect from 1 April 2000 brought into force a new regime for the identification and remediation of contaminated land. Its main objective is to investigate contaminated land that may pose unacceptable risks to human health.

Halton Borough is located in the English County of Cheshire and spans the river Mersey. Major chemical industries have operated in the area for over a century, resulting in a legacy of

\section{Main messages}

- A cohort of subjects residing on an area of contaminated land, through which they were exposed to the known animal nephrotoxin and carcinogen, HCBD, were investigated.

- The cohort showed evidence of subclinical tubular proteinuria and enzymuria.

- These parameters improved when the subjects were reinvestigated, having left their homes for approximately 10 months.

- A number of possible confounding factors are discussed; however, the results suggest that the effects observed are likely to be caused by local environmental factors.

\section{Policy implications}

- It is likely that similar areas of contaminated land will be identified in the UK. Local authorities should obtain public health advice when investigating the potential health risks.

- This study re-emphasises the need to consider potential health implications of developing "brownfield" sites for residential housing. contaminated land. Two former sandstone quarries within the village of Weston, used for the disposal of industrial waste until the early 1970s, were of particular public health concern.

Ground investigations revealed that vapour transport of volatile chemicals was occurring in the vicinity of these quarries. A hazard assessment indicated that the chemical hexachlorobutadiene (HCBD) posed a risk to health. Subsequently, indoor air quality monitoring (IAM) commenced in January 2000 and revealed the presence of this chemical in 20 homes at levels up to 6.8 parts per billion $(\mathrm{ppb})$. In one additional property, the chemical was detected at levels up to 1000 $\mathrm{ppb}$. All these buildings were located immediately to the west of the North Quarry.

HCBD is toxic. ${ }^{2}$ Investigations have shown that its effects in animals are mainly restricted to the kidneys, including carcinogenicity. The effects on human populations, at low levels of exposure via inhalation, are unknown. The American National Occupational Safety and Health Administration (NIOSHA) recommends that exposure to HCBD should not exceed $20 \mathrm{ppb}$ for a eight hour workday within a 40 hour working week.

There were no guidelines on safe levels for residential exposure to HCBD. Therefore, the UK Committee on Toxicity, supported by the Committee on Mutagenicity, reviewed HCBD. Their guidance stated that, for non-carcinogenic effects, levels of exposure to HCBD below $0.6 \mathrm{ppb}$ should not represent a significant risk to health. ${ }^{4}$ Furthermore, the committee believed the carcinogenic risk to be minimal below this level.

A second phase of IAM was conducted in June 2000 and confirmed the original results. However, HCBD was also detected, at levels above $0.6 \mathrm{ppb}$, in six additional adjacent properties.

To safeguard the health of the residents, the local health authority advised that exposure to HCBD should be kept

Abbreviations: CPB, cysteine-S-pentachlorobutadiene; GPB, glutathione-S-pentachlorobutadiene; GST, glutathione-S-transferase; $\mathrm{HCBD}$, hexachlorobutadiene; IAM, indoor air quality monitoring; TCCT, trichlorovinyl-chlorothioketene 


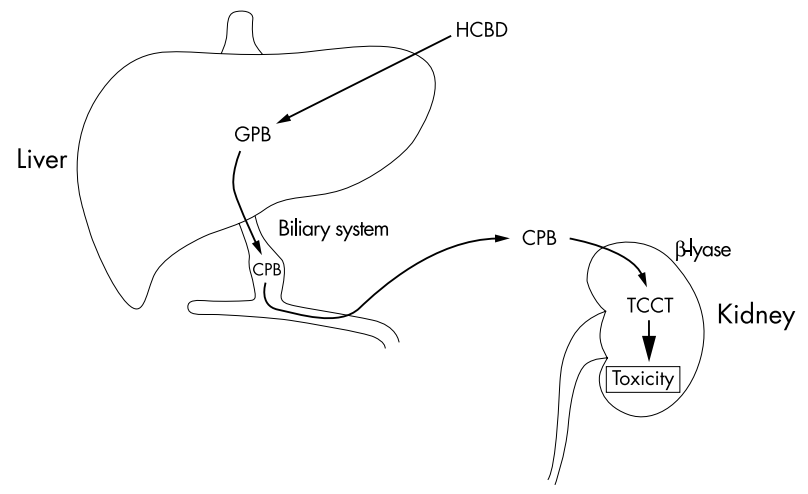

Figure 1 Schematic and simplified diagram of the metabolism and toxicology of $\mathrm{HCBD}$.

below the reference value produced by the Department of Health. Unfortunately, environmental experts concluded that remediation of the houses was impossible and so most subjects elected to leave their homes. ${ }^{5}$

This paper describes the results of the health authority's health investigations.

\section{HCBD_PHYSICAL PROPERTIES AND TOXICOLOGY}

HCBD $\left(\mathrm{C}_{4} \mathrm{Cl}_{6}\right)$ is a by-product of the manufacture of chlorinated hydrocarbons and does not occur naturally. The metabolism and toxicology of HCBD has been studied in experimental animals. Following oral administration, HCBD is conjugated in the liver with glutathione to glutathione-Spentachlorobutadiene (GPB), which is excreted in bile (fig l). After secretion into bile GPB is partially degraded to cysteine$S$-pentachlorobutadiene (CPB) in the bile duct epithelium. ${ }^{6}$ Following enterohepatic recirculation, GPB and CPB are delivered to the kidney where CPB is metabolised in the proximal tubule by the enzyme $\beta$-lyase to the reactive electrophile trichlorovinyl-chlorothioketene (TCCT). ${ }^{7}$ Covalent binding of this final compound to adjacent tissues is responsible for the site specific toxicity of HCBD. ${ }^{8}$

Damage occurs principally in the kidney causing proximal tubular necrosis. ${ }^{90}$ Rats fed very high concentrations of HCBD, for prolonged periods, showed a significant increase in incidence of renal tubular neoplasms compared to controls. ${ }^{2}$ Toxic doses reduce conception rates and birth weights. ${ }^{11}{ }^{12}$

HCBD is also genotoxic. Point mutations can be induced in Salmonella typhimurium by incubating the organism with HCBD in the presence of rat liver. ${ }^{13}$

In vitro human tissues studies have shown that hepatocytes metabolise HCBD to GPB using glutathione- $S$-transferase ${ }^{14}$ and that $\mathrm{CPB}$ causes $\beta$-lyase dependent cytotoxicity to proximal tubular cells. ${ }^{15}$ As human kidney $\beta$-lyase activity is lower in comparison to rats, humans may be less susceptible to HCBD toxicity. ${ }^{16}$
Residents living to the west of the North Quarry were exposed principally by inhalation, which avoids first pass hepatic metabolism of the compound, and so the health effects may differ from those observed in animal investigations. There are few studies of the effect of the compound in vivo in humans and none on the effects of long term inhalation exposure in the residential setting. ${ }^{17}$

The aim of the investigations was to determine whether there was any evidence of harm, or potential harm, in individuals exposed to levels of HCBD in excess of annual average concentrations of $0.6 \mathrm{ppb}$ with special reference to renal disease. Furthermore, to determine whether there was an improvement in abnormalities detected when exposure to HCBD ceased.

\section{METHODS}

\section{Study design}

A longitudinal prevalence study of indicators of renal glomerular and tubular function observed within two months of cessation of long term exposure to HCBD and at least 10 months after exposure ceased.

Subjects in permanent residence at the time that HCBD was detected, at average concentrations in excess of $0.6 \mathrm{ppb}$, were invited to participate in the study. Eighty two subjects were eligible and 70 participated in the first phase of the investigation. Among the 70 who attended there were 15 children aged less than 16 years, 53 subjects aged 16-65, and two subjects aged over 65 years.

Everyone who underwent the first examination was offered a second round of tests. To avoid introducing participation bias, this was completed prior to participants being informed of the initial results. Forty seven subjects (67\%) attended for the follow up examination. This sample comprised 10 children aged less than 16 years, 37 subjects aged 16-65 years, and none over 65 years.

\section{Clinical investigations}

A full medical history was taken from all subjects. ${ }^{18}$ The subjects underwent a physical examination and an ultrasound examination of the liver, biliary system, pancreas, and urinary tract. Blood was examined for routine biochemistry and liver function tests, $\alpha$ fetoprotein, and routine haematological parameters. A 24 hour urine collection was obtained and used to measure creatinine clearance and total urinary protein excretion. Urine was also examined cytologically. Those with microscopic haematuria or atypical urinary epithelial cells were offered cystoscopy. No cases of urinary tract neoplasia or overt renal dysfunction were identified by these methods.

Overt clinical renal disease, from prolonged exposure to chemicals, would only occur after a major part of renal function had been lost. Routine clinical tests are not sufficiently sensitive to be informative, except in the most extreme situations. Therefore a panel of site specific urinary markers of early tubular and glomerular effects were used (table 1).

Table 1 Urinary markers representing different sites of effects in the nephron

\begin{tabular}{lll}
\hline Urinary marker & Site of effect & Reference range \\
\hline Albumin* & Glomerular permeability & $<3.5 \mathrm{mg} / \mathrm{mmol}$ \\
Transferrin & Glomerular permeability & $<0.36 \mathrm{iu} / \mathrm{mmol}$ \\
Retinol binding protein (RBP) & Proximal tubular reabsorption & $<22 \mu \mathrm{mg} / \mathrm{mmol}$ \\
N-acetyl- $\beta$-glucosaminidase (NAG) & Proximal tubular damage (predominantly S1 \&2) & $<1.25 \mathrm{iu} / \mathrm{mmol}$ \\
$\gamma$-glutamyl transferase (GGT) & Proximal tubular cell damage & $<6.0 \mathrm{iu} / \mathrm{mmol}$ \\
Leucine aminopeptidase (LAP) & Proximal tubular brush border cell damage & $<0.8 \mathrm{iu} / \mathrm{mmol}$ \\
$\alpha$ glutathione-S-transferase ( $\alpha$-GST) & Proximal tubular cell damage (predominantly S3) & $<2.2 \mu \mathrm{m} / \mathrm{mmol}$ \\
$\pi$ glutathione-S-transferase ( $\pi$-GST) & Distal tubular cell damage & $<5.8 \mu \mathrm{mm} / \mathrm{mmol}$ \\
\hline
\end{tabular}

Reference ranges are those quoted by the Health and Safety Laboratory (HSL), Sheffield for subjects of working age, and are corrected per mmol of urinary creatinine.

*Occasionally albuminuria can occur as a result of failure of tubular reabsorption. 


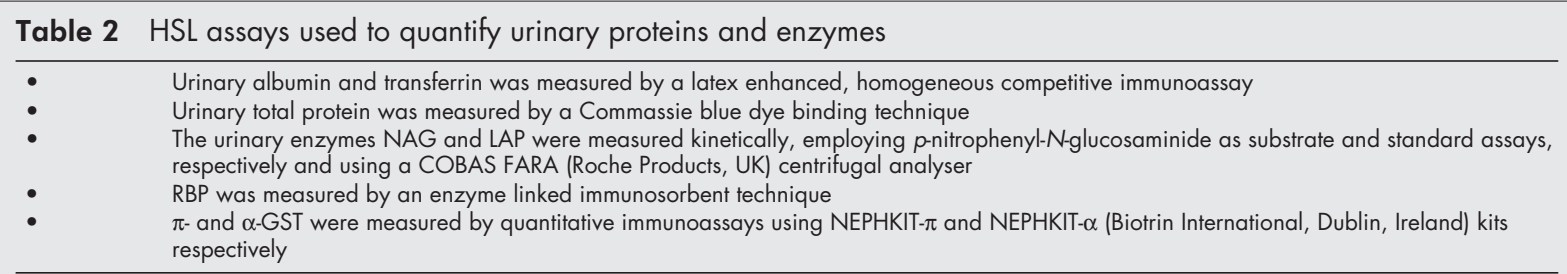

$\pi$-GST is a relatively new marker for distal tubular damage, superseding Tamm-Horsfall protein excretion. ${ }^{28}$ Abbreviations as in table 1.

Table 3 Comparison of urinary protein/enzyme levels shortly after (first round) and at least 10 months (second round) after subjects left their homes

\begin{tabular}{lcccc}
\hline Laboratory test & Mean result in first round & Mean result in second round & t statistic & p value $(2$ tail) \\
\hline Proximal tubular markers & $1.55(0.35)$ & $0.76(0.19)$ & 3.53 & 0.001 \\
$\alpha$-GST & $4.85(0.61)$ & $3.39(0.39)$ & 1.97 & 0.05 \\
GGT & $0.54(0.06)$ & $0.37(0.06)$ & 1.97 & 0.05 \\
LAP & $0.70(0.04)$ & $0.57(0.04)$ & 2.52 & 0.02 \\
NAG & $17.79(11.07)$ & $17.98(8.65)$ & -0.01 & 0.99 \\
RBP & $5.04(1.57)$ & $1.93(0.42)$ & 2.07 & 0.04 \\
Distal tubular marker & $1.21(0.40)$ & $1.09(0.2)$ & 0.37 & 0.71 \\
$\pi$-GST & $0.05(0.02)$ & $0.04(0.02)$ & 0.73 & 0.47 \\
Glomerular markers & & & \\
Albumin & Transferrin* & & & \\
\hline
\end{tabular}

Results are expressed as mean (SEM). $n=47$ except where indicated.

*Follow up results available for 42 subjects.

Abbreviations as in table 1.

The use of a panel of markers to detect early renal disease is well established in a variety of occupational settings, ${ }^{19}$ including investigations into exposure to industrial hydrocarbons ${ }^{2021}$ and cadmium. ${ }^{22}$ While the application of these tests is relatively new in population settings, an almost identical approach has been recommended by the American Agency for Toxic Substances and Disease Registry for case studies of persons exposed to hazardous substances at waste sites. ${ }^{23}$ These measurements have the advantage of being easily made and have great sensitivity but, unfortunately, do not test specifically for nephrotoxic effects of HCBD.

Table 2 summarises the assays used to quantify the urinary markers. The tests were performed at the Health and Safety Laboratory, Sheffield, UK and were subject to internal quality assurance schemes. These procedures ensure that assay drift does not introduce measurement bias. To allow for variations in urinary flow rate and concentration, urine parameters were corrected per millimole creatinine excretion. ${ }^{24}$ The normal ranges for all tests, except $\alpha$ - and $\pi$-GST (glutathione- $S$ transferase), were calculated using $97.5 \%$ centiles from a cohort of 320 working subjects with no history of exposure to nephrotoxins. The ranges for $\alpha$ - and $\pi$-GST are mean \pm 2 SD (taking $\log$ distribution into account) from 72 control subjects. ${ }^{25}$ To make the study group as comparable as possible to "healthy workers", only participants aged 16-65 were included. Also, any participant who was found to have a preexisting renal condition was excluded from the following analysis, as were those known to be taking non-steroidal antiinflammatory drugs.

These investigations were undertaken to deal with the emergency clinical situation that had arisen subsequent to the discovery of the contaminated homes. All subjects gave informed consent to the clinical investigations, and also consented to the pooling of results to enable public health investigations. The residents gave verbal consent to the publication of the pooled results at a meeting with the investigators.

Table 4 Number of abnormal urinary test results shortly after (first round) and at least 10 months (second round) after subjects, aged 16-65, left their homes when compared to the HSL reference range

\begin{tabular}{lcccc}
\hline Test & First round & Percentage & Second round & Percentage \\
\hline Proximal tubular marker & 8 & $22 \%$ & 0 & \\
$\alpha$-GST & 2 & $5 \%$ & 2 & $0 \%$ \\
RBP & 8 & $22 \%$ & 5 & $14 \%$ \\
GGT & 7 & $19 \%$ & 3 & $8 \%$ \\
LAP & 2 & $5 \%$ & 1 & $3 \%$ \\
NAG & & $22 \%$ & 3 & $8 \%$ \\
Distal tubular marker & & $3 \%$ & 1 & $3 \%$ \\
T-GST & 8 & $3 \%$ & 1 & $3 \%$ \\
Glomerular marker & 1 & & & \\
Albumin & 1 & & & \\
Transferrin & & & & \\
\hline
\end{tabular}

*Follow up results available for 42 subjects.

$n=47$ except where indicated.

Abbreviations as in table 1. 


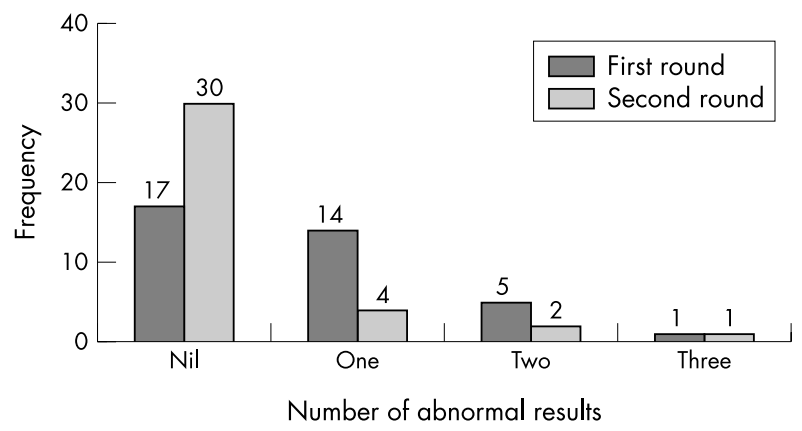

Figure 2 Comparison of number of abnormal proximal tubular markers (table 2) shortly after (first round) and at least 10 months (second round) after subjects left their homes (subjects aged 16-65).

\section{Statistical analysis}

Subjects who completed both rounds of investigations were included in this analysis. The results were compared by two methods. Firstly, the results of first and second round tests were compared by the paired $t$ test. Secondly, the number of abnormal results of proximal tubular tests, in subjects aged 16-65 years, was compared by simple frequency counts.

\section{RESULTS}

Table 3 shows the results of the urinary proteins and enzymes. It can be seen that four of the five proximal tubular markers had significantly decreased in the second round of tests. Similarly, the distal tubular marker, $\pi$-GST, showed a significant decrease. The markers of glomerular function did not show any significant change.

Table 4 shows how many of the tests performed on subjects aged 16-65 years exceeded the HSE laboratory's reference range. Comparison of tables 3 and 4 reveals that while there was a significant decrease in the mean N-acetyl-Dglucosaminidase level, only two participants initially had levels greater than the laboratory reference range.

Figure 2 shows the number of subjects, aged 16-65, with a given number of raised proximal tubular markers when compared to the HSE laboratory's reference population. In the first round of tests 20 (54\%) had at least one abnormal result, and six $(16 \%)$ had two or more raised values. At follow up, the number of subjects with at least one abnormal result had reduced to seven $(19 \%)$. This again shows that the proximal tubular effects improved when the residents left the homes.

\section{DISCUSSION}

This longitudinal study has shown that about half of the adults exposed to HCBD showed evidence of a subclinical proximal tubular effect. Similarly, about a quarter of adults displayed a distal tubular effect. We also found, on subsequent follow up, that in many cases these abnormalities improved when they left their homes. There was no evidence that glomerular function was affected.

In drawing our conclusions about the possible link between these observations and exposure to HCBD, we applied the Bradford-Hill criteria. ${ }^{26}$ The key criteria used here to consider whether HCBD exposure is linked to the renal effects observed are: (1) temporal relation; (2) specificity; and (3) biological plausibility.

A temporal relation is evident when exposure to pollution occurs before onset of effects and, depending on the nature of the effect, is followed by recovery when exposure ceases. In our investigations it has been possible to show the latter part of this relation.

As stated above, the urinary enzyme analyses employed in this investigation do not specifically test for the toxic effects of HCBD. It is possible, though we believe unlikely, that the proximal tubular effect is related to exposure to other chemicals from the quarry or from a nearby petrochemical complex.

These results are consistent with the predicted toxicological effects of HCBD from animal investigations. As the application of these tests is also consistent with biological models, it is highly plausible that these findings are related to exposure to this substance.

The distal effect is more difficult to explain because of the limited exposure assessment undertaken by the company. The site specific toxicity of HCBD in rats is dependent on the restriction of the enzyme $\beta$-lyase to the proximal tubular cells. ${ }^{8}$ This enzyme is responsible for the production of the reactive electrophile trichlorovinyl-chlorothioketene. The distal tubular effect is unlikely to be caused by this compound travelling from the proximal to distal tubule, in the tubular fluid, as it reacts with surrounding tissue far too rapidly. It has been shown that $\beta$-lyase is present in human proximal tubular cells. ${ }^{27}$ We are unaware of any human data regarding its presence in distal tubular cells but this remains nevertheless a possibility.

Thus far, the long term effects of human environmental exposure to HCBD are unknown. Nonetheless, the renal effects noted in this study improved when exposure ceased, and so it is anticipated that the non-carcinogenic risks will be minimal. The future carcinogenic risk is unknown. This data therefore supports the residents' choice to leave their homes, in response to the health authority's advice that they should reduce their exposure.

To improve our understanding of the health effects of exposure to contaminated land, further study of the use of these analytical techniques in population settings is required. To this end we suggest that population and age related reference ranges for the markers of early renal effects are established. These may be applied in a cross sectional study throughout Halton to determine whether residents not exposed to chemicals from Weston Quarry, but living in this highly industrialised area, have increased results. We also suggest that longitudinal follow up studies of the exposed residents are indicated. These studies will improve both our understanding of the human toxicology of HCBD, and of these investigations themselves, so that in future we can be clearer about interpretation of results.

Land contamination exists throughout the UK. In the light of this evidence, and the government's policy of building $60 \%$ of new housing on previously developed land, the public, planning authorities, and development agencies need to be aware of the potential health risks when considering how brownfield sites may be utilised in future.

\section{Authors' affiliations \\ B Staples, Health Protection Agency (North West), Chester, UK M L P Howse, G M Bell, Royal Liverpool University Hospital, Prescot Street, Liverpool L7 8XP, UK \\ H Mason, Health and Safety Laboratory, Broad Lane, Sheffield S3 7HQ, UK}

\section{REFERENCES}

1 DETR. Contaminated land: Environmental Protection Act 1990: Part IIA. DETR Circular 02/2000.

2 Kociba RJ, Keyes DG, Jersey GC, et al. Results of a two year chronic toxicity study with hexachlorobutadiene in rats. Am Ind Hyg Assoc J 1977; 38:589-602

3 National Occupational Safety and Health Administration. Final rule on air contaminants project. Office of the Federal Register, Government Printing Office, Washington, DC. Federal Register 1998;54:2324.

4 Committee on Toxicology. Statement of hexachlorobutadiene. Department of Health, June 2000. Available from http:// www.doh.gov.uk/hcbd.htm.

5 Anon. Blighted. Panorama, BBC 1, 20 March 2000.

6 Gietl YS, Anders MW. Biosynthesis and biliary excretion of S-conjugates of hexachlorobuta-1,3-diene in the perfused rat liver. Drug Metab Dispos $1991 ; 19: 274-7$ 
7 Nash JA, King L, Lock EA, et al. The metabolism and disposition of hexachloro 1,3-butadiene in the rat and its relevance for nephrotoxicity. Toxicol Appl Pharmacol 1984;72:124-37.

8 McFarlane M, Foster JR, Gibson GG, et al. Cysteine conjugate beta-lyase of rat kidney cytosol: characterisation, immunocytochemical localisation, and correlation with hexachlorobutadiene nephrotoxicity. Toxicol Appl Pharmacol 1989;98:185-97.

9 Harlemann JH, Seinen W. Short-term toxicity and reproduction studies in rats with hexachloro-(1,3)-butadiene. Toxicol Appl Pharmacol 1979:47:1-14.

10 Yang RSH, Abdo KM, Elwell MR, et al. Subchronic toxicology studies of hexachloro-1,3-butadiene (hexachlorobutadiene) in B6C3F1 mice by dietary incorporation. J Environ Pathol Toxicol Oncol 1989;9:323-32.

11 Schwetz BA, Smith FA, Humiston CG, et al. Results of a reproduction study in rats fed diets containing hexachlorobutadiene. Toxicol Appl Pharmacol 1977:42:387-98.

12 Harlemann JH, Seinen W. Short-term toxicity and reproduction studies in rats with hexachloro-(1,3)-butadiene. Toxicol Appl Pharmacol 1979;47:1-14

13 Vamvakas S, Kordowich FJ, Dekant W, et al. Mutagenicity of hexachloro-1,3-butadiene and its S-conjugates in the Ames test-role of activation by the mercapturic acid pathway in its nephrocarcinogenicity. Carcinogenesis 1988;9:907-10

14 McLellan LI, Wolf CR, Hayes JD. Human microsomal glutathione-S-transferase. Its involvement in the conjugation of hexachloro-1,3-butadiene with glutathione. Biochem J 1989;258:87-93.

15 Chen JC, Stevens JL, Trifills AL, et al. Renal cysteine conjugate betalyase-mediated toxicity studied with primary cultures of human proximal cells. Toxicol Appl Pharmacol 1990;103:463-73

16 Green T, Odum J, Nash JA, et al. Perchloroethylene-induced rat kidney tumours: an investigation of the mechanisms involved and their relevance to humans. Toxicol Appl Pharmacol 1990;103:80-9.
17 Burkatskaya EN, Viter VF, Ivanova ZV, et al. [Clinico-hygienic data on working conditions during use of hexachlorobutadiene in vineyards] (in Russian). Vrach Delo 1982;11:99-102.

18 Yaqoob M, Bell GM, Stevenson A, et al. Renal impairment with hydrocarbon exposure. Q J Med 1993,86:165-74.

19 Lauwerys RR, Bernard A. Early detection of the nephrotoxic effects of industrial chemicals: state of the art and future prospects. Am J Ind Med $1987 ; 11: 275-85$

20 Mutti A, Alinovi R, Bergamaschi E, et al. Nephropathies and exposure to perchloroethylene in dry-cleaners. Lancet 1992;340:189-93.

21 Viau C, Bernard A, Lauwerys R, et al. A cross-sectional survey of kidney function in refinery employees. Am J Ind Med 1987;1 1:177-87.

22 Chia KS, Ong CN, Ong HY, et al. Renal tubular function of workers exposed to low levels of cadmium. Br J Ind Med 1989;46: 165-70.

23 Lybarger JA, Lichtveld MY, Amler RW. Biomedical testing of the kidney for persons exposed to hazardous substances in the environment. Ren Fail 1999;21:263-74

24 Mason HJ, Williams NR, Morgan MG, et al. Influence of biological and analytical variation on urine measurement for monitoring exposure to cadmium. Occup Environ Med 1998;55:132-7

25 Health and Safety Laboratory, Sheffield, UK. Unpublished data.

26 Bradford-Hill A. The environment and disease: association or causation? Proc R Soc Med 1966;58:295

27 Chen JC, Stevens JL, Trifillis AL, et al. Renal cysteine conjugate beta-lyase-mediated toxicity studied with primary cultures of human proximal tubular cells. Toxicol Appl Pharmacol 1990;103:463-73.

28 Sundberg AGM, Appelkvist E-L, Bacman L, et al. Urinary pi-class glutathione transferase as an indicator of tubular damage in the human kidney. Nephron 1994;67:308-16.

\section{BMI 3rd Asia Pacific Forum on Quality Improvement in Health Care

We are delighted to announce this forthcoming conference in Auckland, New Zealand.

The themes of the 3rd Asia Pacific Forum on Quality Improvement in Health Care are:

- Agenda for quality: Improving equity in health care delivery

- Improving safety

- Leadership for improvement

- Measuring quality and benchmarking for change

- Evidence based knowledge and education for quality improvement

- Improving health systems

- Patient/consumer centred quality improvement

Presented to you by the BM Publishing Group (London, UK) and Institute for Healthcare Improvement (Boston, USA), supported by the New Zealand Ministry of Health, ACC, and Standards New Zealand.

For more information about the Forum or to register contact: quality@bma.org.uk or go to:

www.quality.bmipg.com

Tel: +44 (0)2073836409 Fax: +44 (0)2073836869 